\title{
Prostatic Atypical Adenomatous Hyperplasia
}

National Cancer Institute

\section{Source}

National Cancer Institute. Prostatic Atypical Adenomatous Hyperplasia. NCI Thesaurus.

Code C5595.

A prostatic hyperplasia characterized by the presence of crowded adenomatous epithelial nodules. 